\title{
The interaction of habit (H) and drive (D) in classical eyelid conditioning: $H$ as a function of UCS intensity and trials, D as a function of UCS intensity and anxiety'
}

\author{
JOHN J. PORTER AND JAMES J. HUG 2 \\ UNIVERSITY OF WISCONSIN, MILWAUKEE
}

In two experiments Spence's postulate of habit-drive multiplication was tested by varying UCS intensity $(0.75$ psi or $2.0 \mathrm{psi}$ ) and manifest anxiety (MA) level over a series of 160 conditioning trials. Generally, there was a tendency for the performance of high-low $M A$ groups to diverge over trials 1-80 and converge over trials 81-160; this same trend was apparent in prior studies using fewer trials.

In the present experiments the implications of the $\mathbf{E}=\mathbf{H} \times \mathbf{D}$ postulate were examined over a more extended series of trials than in previous studies in order to assess the convergence between high and low D groups noted by Prokasy and by Hug \& Porter (in press). The second of the two experiments varied UCS Intensity in addition to MA in order to examine the effects of MA at two levels of $H$ as well as $D$. Thus it was possible to examine the effects of one drive-producing variable (MA) over trials in conjunction with two combinations of $\mathrm{D}$ and $\mathrm{H}$, defined by two UCS Intensities.

Experiment 1

Method. Forty-three male introductory psychology students were used. Four Ss were discarded as voluntary responders using the latency criterion of Spence \& Ross (1959). Of the remaining 39, 20 were defined as high $D$ on the basis of MA scores above the 75th percentile; 19 were classed as low D with MA scores below the 25 th percentile.

All Ss were seated in a dental chair in a $5 \times 7 \mathrm{ft}$ sound-insulated room, illuminated by a $7.5 \mathrm{~W}$ amber light behind and above S. A $55 \mathrm{~dB}, 660 \mathrm{cps}$ tone was used as a masking noise. Details of the recording technique are provided in Hug and Porter. A small neon bulb, located $3 \mathrm{ft}$ from $S$ behind a 2 in. diameter ground-glass disc, served as a fixation point, while four additional bulbs served as a CS of $550 \mathrm{msec}$ duration. The 0.75 psi airpuff UCS was delivered to the right eye during the last $50 \mathrm{msec}$ of CS duration. A buzzer served as a ready signal.

After being instructed to relax, to fixate on the disc, and not attempt to control the responses of his eyes, $S$ was given three CS-alone trials and one UCSalone trial, immediately followed by a series of 160 conditioning (CS-UCS) trials. The ready signal preceded the CS by an average of $3 \mathrm{sec}$.

The data were scored using the latency criterion for a CR (Spence \& Ross, 1959); any eyelid deflection of $1 \mathrm{~mm}$ or more, 200-500 msec after CS onset, was considered a CR while responses in the interval 200-300 msec after CS-onset were classed as voluntary responses.

Results. Analyses were based primarily on E (Spence, 1956, p. 104) using all responses in the interval 200-500 msec after CS-onset, although the data were also analyzed in terms of percentage-CR. However, this latter data was not reported since the theory is stated in terms of $\mathrm{E}$ and the percentage-CR analyses yielded similar results.

High MA Ss made significantly more CRs than low MA Ss $(F=103.88$, df $=1 / 37, p<.001)$. The increment in CRs over blocks of 20 trials was also significant $(F=27.22, \mathrm{df}=7 / 259, \mathrm{p}<.001)$, and the interaction of these variables was rellable $(F=3.11$, $d f=7 / 259, p<$ .01). Following Prokasy, rank-order correlation coefficients (rho) were computed for the between-group difference in $E$ over blocks of 10 trials. It can be seen from the left column of Table 1 that the groups did diverge up to Trial 80 , rho $=+1.00, p<.01$; thereafter, the between-group difference decreased systematically over the final 80 trials, yielding a rho of -.98 , $p<.01$, for Trials 81-160.

\section{Experiment 2}

Experiment 1 was replicated with female $\mathrm{Ss}$ with the addition that high and low MA groups were conditioned with either a 2.0 or 0.75 psi air puff, forming a 2 by 2 factorial design.

Method. Eighty-four female introductory psychology students were used. One $\mathrm{S}$ was discarded as a voluntary responder and one for failure to reach a level of $20 \%$ CR over the final 20 trials. Of the remaining 82, 44 were defined as high $D$ on the basis of MA scores above the 75 th percentile, and 38 were classed as low D because of MA scores below the 25th percentile. One-half of each D group was conditioned with an 0.75 psi air puff, the remainder with a 2.0 psi UCS. Thus, there were $22 \mathrm{Ss}$ in Group $2.0 \mathrm{H}, 22$ in Group $0.75 \mathrm{H}, 19$ in Group $2.0 \mathrm{~L}$, and 19 in Group $0.75 \mathrm{~L}$. In all respects, the apparatus and experimental procedure were identical to those of the first study, with the exception of the added UCS intensity mentioned above.

Results. Analyses were conducted over blocks of 20 trials in terms of $\mathrm{E}$. The main effects of all three 
variables were highly reliable: for UCS intensity$\mathrm{F}=31.41, \mathrm{df}=1 / 78$; for $\mathrm{MA}-\mathrm{F}=13.68, \mathrm{df}=1 / 78$, and for blocks of trials $-\mathrm{F}=68.10, \mathrm{df}=7 / 546$, with all $\mathrm{p}<.001$. There was no evidence of a UCS by MA interaction ( $F=0.09, \mathrm{df}=1 / 78, \mathrm{p}>.20$ ), but the MA by Trials interaction was significant $(F=2.16, d f=7 / 546, p<$ $.05)$. However, the triple interaction between UCS intensity, MA level, and Trials, predicted by the $\mathrm{H} \times \mathrm{D}$ postulate, was not significant $(\mathrm{F}=1.82, \mathrm{df}=$ $7 / 546, .05<\mathrm{p}<.10$ ).

Although the triple interaction was not reliable, the fact that this interaction approached the .05 level prompted separate tests of the MA by Trials effect at each level of UCS intensity. These tests were conducted to see if there was any evidence for the predicted interaction at the separate $\mathrm{H}$ and $\mathrm{D}$ levels. With the weaker UCS, the MA by Trials interaction was significant $(\mathrm{F}=6.81, \mathrm{df}=7 / 273, \mathrm{p}<.001)$; however, the same interaction was not reliable in the 2.0 groups $(\mathrm{F}=0.28, \mathrm{df}=7 / 273, \mathrm{p}<.20)$. Examining the middle column of Table 1, the maximum $D$ difference for the 0.75 groups occurred between trials 91-110 and decreased somewhat thereafter. The correlations obtained separately for Trials 1-80 (.31) and 81-160 (-.69) were not significant, while the overall correlation, rho $=.60, p<.02$, over Trials $1-160$ was significant. For the 2.0 groups, there appeared to be no systematic relationship between MA difference and Trials over Trials 1-80, but over Trials $81-160$ a rho $=-.74$, $p<.01$, indicated significant convergence.

The amplitudes of the UCRs were examined for evidence of adaptation over trials, and especially differential adaptation over trials, and especially differential adaptation in high D Ss. Analysis of mean UCR amplitude over Trials 1-10, 81-90, and 151-160 over all groups showed no evidence of differential adaptation, although the overall decrease in UCR amplitude was reliable $(\mathrm{F}=35.23, \mathrm{df}=2 / 144, \mathrm{p}<.001)$. Discussion

The evidence from Prokasy (1967), Hug \& Porter (in press), and the present study suggests that the $\mathrm{H}$ $\mathrm{x}$ D postulate reliably predicts conditioning performance up to 60-80 trials after conditioning begins. The convergence in performance observed thereafter in these studies may have been due to a decrease in $D$ through adaptation (Taylor, 1956). Another source of the convergence might be Ss' knowledge of the impending termination of the experiment. Despite the fact that $S$ 's watch was removed in the present experiments, and in Hug \& Porter, Ss could still estimate the $1 \mathrm{~h}$ time interval used. Such estimation, with the attendant possibility of relaxation near the end of the interval, might have been the source of the observed
Table 1

Between-group (MAS) Difference Over Trials, High Minus Low MAS in E Units

\begin{tabular}{llll} 
Trials & $0.75 \mathrm{M}$ & $0.75 \mathrm{~F}$ & $2.00 \mathrm{~F}$ \\
\hline $1-10$ & .49 & .21 & .59 \\
$11-20$ & .79 & .16 & .64 \\
$21-30$ & 1.01 & .37 & .41 \\
$31-40$ & 1.36 & .06 & .47 \\
$41-50$ & 1.40 & .06 & .58 \\
$51-60$ & 1.98 & .14 & .49 \\
$61-70$ & 2.10 & .42 & .85 \\
$71-80$ & 2.04 & .71 & .88 \\
$81-90$ & 1.95 & 1.10 & .88 \\
$91-100$ & 1.80 & 1.40 & .49 \\
$101-110$ & 1.75 & 1.43 & .65 \\
$111-120$ & 1.20 & .82 & .52 \\
$121-130$ & .98 & 1.07 & .44 \\
$131-140$ & 1.08 & 1.37 & .26 \\
$141-150$ & .89 & .69 & .48 \\
$151-160$ & .66 & .35 & .45 \\
\hline Rho: trials $1-80$ & $1.00,(\mathrm{p}<.01)$ & .31 & .40 \\
Rho: trials $81-160$ & $-.98,(\mathrm{p}<.01)$ & -.69 & $-.74,(\mathrm{p}<.05)$ \\
Rho: trials $1-160$ & -.06 & $.60,(\mathrm{p}<.02)$ & -.25 \\
\hline
\end{tabular}

convergence. On puzzling fact was that the magnitude of the high-low MA difference of Table 1 was much greater for male Ss than female Ss. While the authors have no completely satisfactory explanation of this result it is worth noting that the male ss were run late in the semester and had been introduced to classical conditioning, while the female Ss were run early in the semester and were not familiar with classical conditioning. Possibly the male-female performance differences were a function of this difference in knowledge of classical conditioning procedures.

\section{References}

HUG, J. J., \& PORTER, J. J. The interaction of Habit (H) and Drive (D) in classical eyelid conditioning: $H$ and $D$ as functions of UCS intensity. J. exp. Psychol, in press.

PROKASY, W. F. Do D and $\mathrm{H}$ multiply to determine performance in human conditioning? Psychol. Bull., 1967, 67, 368-377.

SPENCE, K. W. Behavior theory and conditioning. New Haven: Yale University Press, 1956.

SPENCE, K. W. A theory of emotionally based drive (D) and its relation to performance in simple learning situations. Amer. Psychologist, 1958. 13, 131-141.

SPENCE, K. W., \& ROSS, L. E. A methodological study of the form and latency of the eyelid response in conditioning. J. exp. Psychol., 1959, $58,376-381$.

TAYLOR, J. A. Level of conditioning and intensity of the adapting stimulus. J. exp. Psychol, 1956, 51, 127-130.

Notes

1. This research was supported by NIMH Grant MH-12582-01 to the first author.

2. Now at the University of Toronto. 